\title{
Developmental Benefits of Extracurricular Involvement: Do Peer Characteristics Mediate the Link Between Activities and Youth Outcomes?
}

\author{
Jennifer A. Fredricks ${ }^{1}$ and Jacquelynne S. Eccles $^{2}$
}

Received August 30, 2004; revised May 11, 2005; accepted May 25, 2005

\begin{abstract}
In this article, we test: (a) the relation between school-based extracurricular participation and indicators of positive and negative development across a range of activity contexts, and (b) a mediation model linking activity participation, prosocial peers, and development. Extensive survey information was collected from a predominately White sample of middle class adolescents in 9th, 10th, and 12th grades. Extracurricular participation was related to more favorable academic, psychological, and behavioral adjustment; the pattern of findings differed by activity and outcome. In addition, we documented some support for the hypothesis that the link between extracurricular participation and positive adjustment is partly a function of associating with a prosocial peer group. Implications of these findings and suggestions for future research are presented.
\end{abstract}

KEY WORDS: extracurriculars; peers; youth development.

Adolescents in the United States spend more than half of their waking hours in leisure activities (Larson and Varma, 1999). Both scholars and youth policy advocates argue that participation in extracurricular activities, such as sports, the arts, and school clubs, are a productive use of this leisure time and can provide distinct opportunities for growth and development (Eccles and Gootman, 2002; Larson, 2000). These contexts share several features that are directly linked to positive development, including regular participation schedules, direction by an adult leader, emphasis on skill development, and involvement that requires sustained attention, opportunities for meaningful participation, and clear feedback (Eccles and Gootman, 2002).

\footnotetext{
${ }^{1}$ Assistant Professor of Human Development, Connecticut College. Received her $\mathrm{PhD}$ in 1999 from the University of Michigan. Major research interests include motivation, school engagement, extracurricular participation, and adolescent development. To whom correspondence should be addressed at Connecticut College, Box 5308, 270 Mohegan Avenue, New London, Connecticut 06320; e-mail: jfred@conncoll.edu.

${ }^{2}$ MacKeachie Collegiate Psychology Professor, University of Michigan. Received PhD in 1974 from the UCLA. Recent work focuses on ethnicity and the transitions from middle childhood to adolescence and into adulthood.
}

Several explanations have been proposed for why participation in extracurricular activities is a beneficial use of adolescents' time. First, the more that time adolescents are involved in structured activities, the less time they have to engage in problematic behaviors (Mahoney and Stattin, 2000; Osgood et al., 1996). Second, individuals often choose to participate in extracurricular activities because they are intrinsically interested in the activity, and thus these settings provide an opportunity for them to demonstrate effort, persistence, and concentration, as well as explore their identities (Eccles and Barber, 1999; Larson, 2000). Third, these activities provide opportunities to link adolescents to supportive adults outside the classroom (McLauglin, 2000). Finally, activity participation facilitates membership in a prosocial peer group (Eccles and Barber, 1999; Mahoney et al., 2005).

This study has 2 parts. In the 1st set of analyses, we examine variations in the relation between extracurricular participation and indicators of positive and negative development across a range of extracurricular contexts. The prior literature has overemphasized sports participation or has tended to lump all extracurricular activities together into a single measure (Holland and Andre, 1987). Building on work by Eccles and Barber (1999), 


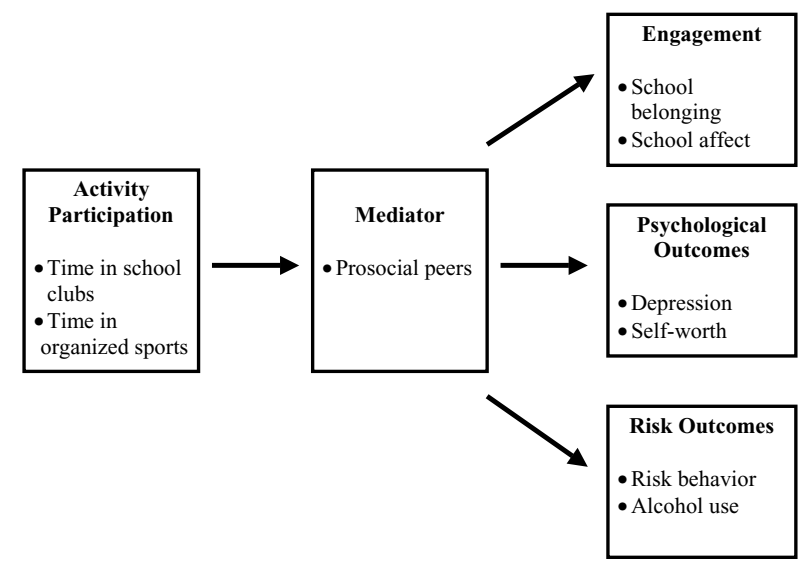

Fig. 1. Mediational model of activity participation, prosocial peers, and developmental outcomes.

we focus on 4 school-based extracurricular activities: (1) team sports, (2) school involvement activities (i.e., student government, cheerleading, and pep club), (3) performing arts (i.e., band, dance, and drama), and (4) academicallyoriented clubs. In the 2nd set of analyses, we examine the hypothesis that extracurricular participation leads to more favorable outcomes because it facilitates membership in a prosocial peer group (see Fig. 1). Few studies have evaluated theoretically based hypotheses about the mechanisms likely to mediate the association between activity participation and development (Eccles et al., 2003). We use guidelines by Baron and Kenny (1986) to test a theoretically based hypothesis-do perceived values and behaviors of the peer group mediate the link between time in organized activities and indicators of positive and negative adjustment. In the next section, we review the relevant literature on extracurricular activities, peers, and adolescent development that are relevant to the 2 sets of analyses.

\section{Correlates of Extracurricular Participation}

Converging evidence from sociology, leisure studies, sport psychology, and adolescent development demonstrate the beneficial effects of extracurricular involvement. Organized activity participation has been associated with academic outcomes including achievement, school engagement, and school satisfaction (Cooper et al., 1999; Eccles and Barber, 1999; Marsh and Kleitman, 2002). Other work has demonstrated a link between participation and emotional adjustment including higher self-esteem and lower depression (Barber et al., 2001; Mahoney et al., 2002). Involvement in extracurricular activities also has been shown to reduce the likelihood of engaging in risky or delinquent behavior and abusing various substances (Mahoney and Cairns, 1997; Youniss et al., 1997). Despite these benefits, some studies have shown negative consequences of involvement in certain types of activities. For example, athletic involvement has been linked to higher rates of alcohol use (Eccles and Barber, 1999). Others have noted the negative peer dynamics in less structured leisure activities that encourage the promotion of undesirable social norms (Eder and Parker, 1987; Mahoney and Stattin, 2000). Because of the potential benefits and costs of involvement, it is important to include indicators of both positive and negative adjustment in the same study.

\section{Extracurricular Activities and Peers}

The extracurricular literature has been criticized for the lack of empirical studies that directly test the mechanisms by which activity participation is linked to development (Brown, 1988; Eccles et al., 2003). One such hypothesis is that participation facilitates membership in a prosocial peer group (Eccles and Barber, 1999; Mahoney et al., 2005). Involvement in school-based extracurricular activities helps to determine how adolescents spend their time, it influences their selection of friends, and helps to shape the norms and values to which they are exposed to. Adolescents in organized activities are more likely to associate with nondeviant peers who value academics and conventional activities (Eccles and Barber, 1999; Mahoney, 2000). These peer groups develop an activity-based culture with shared norms and values (Brown, 1990). It is likely that the collective values and behaviors of these peer groups will, in turn, influence individual members.

Several scholars have explored the link between peers, activities, and development, but no study has tested the full mediational model in 1 analysis. For example, Eccles and her colleagues have conducted extensive research on peers and activities with data collected from a sample of working class youth in the late 1980s (see Barber et al., 2001; Eccles et al., 2003; Eccles and Barber, 1999). They found that adolescents in extracurricular activities have more friends who plan on attending college and are doing well in school than do adolescents who do not participate in these activities. Having more academically focused and less risky peers was predictive of achievement and risk behaviors, while being part of a risky peer network was associated with increased involvement in antisocial behaviors and decreased odds of going to college. Additional evidence of the synergistic links between activities and peers comes from the ethnographic literature. These studies illustrate how participation in high school based activities influences one's peer group and 
one's status within the school. In turn, the peer cultures strongly shape the individual's values and behaviors (Eckert, 1989; Eder and Parker, 1987). Finally, other studies illustrate the protective benefits of having peers who participate in extracurricular activities including a reduction in antisocial patterns (Mahoney, 2000) and social alienation (Kinney, 1993).

\section{Peer Influences on Adolescent Development}

Peers may exert either a positive or negative influence on adolescent development, depending on the characteristics of the peer group (Berndt, 1992). In this section, we briefly review the key findings from the research linking peer characteristics to risk behavior, academic adjustment, and emotional well-being. We begin with research on the influence of deviant peers since more literature has tested this question than has explored the link between positive peer characteristics and development.

A consistent finding is that adolescents with delinquent peers are more likely to become delinquent themselves (see Elliot et al., 1985; Lipsey and Derzon, 1998). Another widely replicated finding is that adolescents' alcohol and drug use can be predicted from the alcohol and drug use of both close friends and larger friendship groups (e.g., Hawkins et al., 1992; Urberg et al., 1997). Other research has explored the link between peer characteristics and academic outcomes. Evidence from this work demonstrates that children and adolescents are similar to their peers in engagement and achievement levels and this similarity increases over time (Berndt and Keefe, 1995; Kindermann, 1993; Ryan, 2001). Research on peer influences on emotional adjustment has focused more on the impact of peer victimization and rejection and on the quality of peer relationships (e.g., Hawker and Boulton, 2000; Keefe and Berndt, 1996) than on how friends' characteristics influence psychological development. The studies on peer characteristics that have been conducted show that associating with deviant peers (Brendgen et al., 2000) and distressed peers (Hogue and Steinberg, 1995) is predictive of depression and internalizing problems over time.

\section{Purpose}

In the 1 st set of analyses, we examine the relation between extracurricular participation and indicators of positive and negative adjustment across a range of extracurricular contexts (i.e., sports, school involvement activities, performing arts, and academic clubs). Based on the prior literature, we hypothesize that activity participation will be a positive predictor of school belonging, school affect, and self-worth, and a negative predictor of depression, substance use, and risk taking behaviors. We also expect to document differences in the patterns by activity type and outcome. For example, we predict that athletic participation will be a predictor of higher alcohol use and that involvement in academic clubs will be associated with lower substance use.

In the 2nd set of analyses, we test a mediation model linking time in organized activities, peers, and adolescent development (see Fig. 1). A direct relation between time in organized activities and our indicators of academic, psychological, and behavioral adjustment is expected. Based on the literature on peers and activities, adolescents who spend more time in school clubs and more time in sports are expected to have more prosocial peers. Further, we hypothesize that having a higher proportion of prosocial peers will be a positive predictor of school engagement and self-worth and a negative predictor of depression, substance use, and risky behaviors. Finally, we predict that the links between time in activities and adjustment will be reduced when we take into account characteristics of the peer group.

\section{METHOD}

This paper uses data from the Childhood and Beyond Study (CAB), a larger study of activity choice in childhood and adolescence conducted by Jacquelynne Eccles and her colleagues at the University of Michigan. This study began with 3 cohorts of children in kindergarten, 1st, and 3rd grade in public elementary schools; these 3 cohorts have been followed over 8 waves of data collection through the high school years and into their twenties. Because we were interested in the consequences of high school participation, we used survey information collected during the 7th wave of data collection when the youth were in 9th, 10th, and 12th grade.

The sample includes 498 adolescents $(54 \%$ female and $46 \%$ male). One hundred fifty-two participants were in 9 th grade, 151 were in 10th grade, and 184 were in 12th grade. Sample sizes differ slightly across analyses due to missing data on some indicators. In general, participants were European American (95\%), with a small minority population of African Americans, Native Americans, Asians, and Hispanics. These participants lived in 3 middle-class communities near Detroit. This sample was explicitly selected so that family income and neighborhood resources would not be obstacles to parents providing opportunities to support their children's activity involvement. 


\section{Measures}

Adolescents filled out surveys in their classrooms with a range of constructs including items about activity involvement, school engagement, academic performance, psychological adjustment, characteristics of the peer group, and risk behavior. In addition, mothers and fathers of each participant completed surveys with information on demographic factors during the 1 st 4 waves and 6 th wave of data collection. A list of the items used in the analyses is presented in the Appendix.

\section{Activity Involvement}

Adolescents were given a detailed list of structured activities and were asked to check off all of the activities that they participated in at school. These activities were aggregated into 4 categories: team sports-participating in 1 or more sport teams; school involvement - participating in 1 or more of the following activities: student government, pep-club, and/or cheerleading; performance arts activities - participating in 1 or more of the following activities: school band, drama, dance, and/or art; and academic clubs-participating in 1 or more academically related clubs. The dichotomous measures of activity participation were used in the 1 st set of analyses.

In addition, participants were asked 2 questions about how much time they spent in organized sports and how much time they spent in school clubs and organizations. They were asked to indicate the frequency of each activity during a typical week: 1 : none, $2: 1$ hor less, $3: 2-3 h, 4: 4-$ 6 h, 5: 7-10 h, 6: 11-15 h, 7: 16-20 h, 8: 21 or more $h$. The time use measures were used in the 2 nd set of analyses.

\section{School Engagement}

School belonging and school affect were included as indicators of school engagement. The scale measuring school belonging consisted of 5 items about adolescents' perceptions that they mattered, belonged, or felt left out in school ( $\alpha=0.79,5$ items). All of the items were assessed on a 7-point scale (1: never, 7: all of the time). We measured school affect with one 7-point item about how much they liked school this year as compared to last year (1: a lot less, 7: a lot more).

\section{Psychological Outcomes}

Depression and self-worth were included as indicators of psychological adjustment. Adolescents were asked to report how frequently they had experienced depressive symptoms in the past month ( $\alpha=0.87,9$ items). In addition, Harter's self-worth scale (1985) was used as our measure of self-worth ( $\alpha=0.81,7$ items). The scale consisted of 7 items about adolescents' general evaluations of the way they do things, feel about themselves, act, and whether they feel like they are good persons. The response scale ranged from 1 to 4 , with higher numbers signifying higher self-worth.

\section{Risk Behaviors}

Adolescents reported on the frequency of their involvement in a variety of risk behaviors in the previous 6 months. A scale measuring risk behaviors was created. This scale contained items such as skipping school, getting into fights, and damaging private property $(\alpha=0.77$, 7 items). A separate scale was created to assess alcohol use ( $\alpha=0.95,2$ items) because prior research has documented higher rates of drinking among athletes (Eccles and Barber, 1999).

\section{Prosocial Peers}

Detailed information about the characteristics of the respondents' peer group was collected. Adolescents were asked a series of questions about their perceptions of how many of their friends engaged in prosocial activities, such as encouraging them to do their best in school and attending religious activities (1: none of my friends, 7: all of my friends). A scale assessing adolescents' perceptions of prosocial peers was created ( $\alpha=0.75,6$ items).

\section{Controls}

Gender, grade-level, parent education, and grade point average (self-reported 1st semester grades) were included as covariates. Since participation in extracurricular activities is voluntary, differences in the outcomes between participants and nonparticipants may reflect preexisting differences between the 2 groups (Holland and Andre, 1987). Because of self-selection concerns, we thought it was important to control for gender, age, socioeconomic status, and academic ability because these variables have emerged as predictors of activity participation in previous studies (e.g., Holland and Andre, 1987; Marsh and Kleitman, 2002). Demographic factors and academic ability are also correlates of school engagement, psychological adjustment, and risky behaviors (e.g., Lerner and Steinberg, 2004), and failing to control for these factors overstates the developmental benefits of activity involvement. 
An index was created to characterize the highest level of parent education from mothers' and fathers' reports of educational attainment on a list of precoded responses (1: grade school, 10: advanced professional degree). We used all available data collected from parents to create this measure. Since 131 adolescents had missing data on parent education for both parents, we imputed the mean parent education level for these participants. A dummy variable (1: full parent data, 0: mean imputed for missing data) was included in all analyses to test if adolescents in families where we imputed the mean for parent education were systematically different from adolescents in families with parent education information. In all but 1 analysis, ${ }^{3}$ the dummy variable for missing data was not significant, suggesting that imputing information on this variable was not biasing our sample.

\section{ANALYSES I: DEVELOPMENTAL OUTCOMES BY ACTIVITY CONTEXT}

\section{Descriptive Patterns}

The total number of activities was computed by summing adolescents' reports of involvement across each of the activity contexts (i.e., team sports, school involvement activities, performing arts, and academic clubs). In this sample, participants were heavily involved in extracurricular activities, with $79 \%$ of individuals reporting that they were involved in at least 1 activity. The mean number of activities was 1.79 , with a range of $0(N=105)$ to 4 or more $(N=62)$ activities. Females participated in an average of 1.93 activities compared with 1.62 activities for males $(F[1,496]=4.69 ; p<0.01)$. The mean number of activities was not significantly different by grade-level. Respondents had the highest involvement in sport teams $(N=259)$ and the lowest participation rates in school-involvement activities $(N=83)$. Overall, there were no gender differences in athletic involvement. However, there were significant differences in participation rates across different athletic teams. For example, males were more likely to be involved in baseball and females were more likely to participate in volleyball. Females also were more likely than males to be involved in each of the other activity contexts $\left(\chi^{2}=9.73\right.$; $p<0.01)$. Females had higher participation in school involvement activities $\left(\chi^{2}=18.54 ; p<0.01\right)$, perform-

\footnotetext{
${ }^{3}$ The dummy for missing data was significant in the ANCOVA for performing arts by prosocial peers; adolescents with parent data had more favorable ratings of their peers than adolescents in which we had imputed the mean for parent education.
}

ing arts, $\left(\chi^{2}=12.51 ; p<0.001\right)$, and academic clubs $\left(\chi^{2}=6.96, p<0.01\right)$ than did males.

A series of ANCOVAs were run to compare the means of participants and nonparticipants in team sports, school involvement activities, performing arts, and academic clubs for each outcome, controlling for gender, grade-level, parent education, and grade point average. In addition, we compared participants in any extracurricular activity to nonparticipants on each of the outcomes. Table I presents the means and standard deviations by domain and outcome.

\section{Team Sports}

Athletic participation was associated with higher perceptions of school belonging $(F[6,455]=9.20, p<$ $0.01)$ and higher reports of alcohol use $(F[6,455]=4.21$, $p<0.05)$. In addition, athletes had marginally more favorable attitudes toward school $(F[6,454]=3.79, p<$ $0.10)$ and a marginally higher percentage of prosocial peers than did nonathletes $(F[6,455]=3.32, p<0.10)$. Furthermore, athletes had marginally lower rates of depression than did nonathletes $(F[6,455]=3.79, p<$ $0.10)$. After controlling for some self-selection factors, athletic participation was not associated with either selfworth or risk behaviors.

\section{School Involvement Activities}

We also documented several differences in the developmental outcomes between respondents who participated in school involvement activities and those who did not. Controlling for some self-selection factors, participation was associated with higher school belonging $(F[6,455]=17.03 ; p<0.001)$, higher selfworth $(F[6,455]=9.49 ; \quad p<0.01)$, prosocial peers $(F[6,455]=14.71 ; p<0.001)$, and lower depression $(F[6,455]=6.22 ; p<0.05)$. In addition, adolescents in school involvement activities had marginally more positive attitudes toward school than nonparticipants $(F[6,454]=3.51, p<0.10)$. There were no differences in the level of risk behavior between participants and nonparticipants in school involvement activities.

\section{Performing Arts}

Participants in the performing arts had lower rates of alcohol use $(F[6,455]=5.94, p<0.05)$ and more favorable perceptions of their peer group $(F[6,455]=$ 5.76, $p<0.05$ ) than did nonparticipants. On all other indicators, the relation between activity participation and 
Table I. Means and Standard Deviations of Outcomes by Participation in Extracurricular Activities

\begin{tabular}{|c|c|c|c|c|c|c|c|c|c|c|}
\hline & \multicolumn{2}{|c|}{ Sport team } & \multicolumn{2}{|c|}{ School involvement } & \multicolumn{2}{|c|}{ Performing arts } & \multicolumn{2}{|c|}{ Academic clubs } & \multicolumn{2}{|c|}{ Any activity } \\
\hline & No & Yes & No & Yes & No & Yes & No & Yes & No & Yes \\
\hline School belonging & $\begin{array}{c}4.80 \\
(1.20)\end{array}$ & $\begin{array}{l}5.16^{* *} \\
(1.08)\end{array}$ & $\begin{array}{c}4.91 \\
(1.13)\end{array}$ & $\begin{array}{l}5.44^{* * *} \\
(1.17)\end{array}$ & $\begin{array}{c}5.00 \\
(1.14)\end{array}$ & $\begin{array}{c}5.00 \\
(1.15)\end{array}$ & $\begin{array}{c}4.96 \\
(1.15)\end{array}$ & $\begin{array}{c}5.11 \\
(1.17)\end{array}$ & $\begin{array}{c}4.76 \\
(1.15)\end{array}$ & $\begin{array}{c}5.11^{*} \\
(1.17)\end{array}$ \\
\hline School affect & $\begin{array}{c}4.56 \\
(1.82)\end{array}$ & $\begin{array}{r}4.92^{\dagger} \\
(1.60)\end{array}$ & $\begin{array}{c}4.69 \\
(1.72)\end{array}$ & $\begin{array}{r}5.07^{\dagger} \\
(1.64)\end{array}$ & $\begin{array}{c}4.75 \\
(1.76)\end{array}$ & $\begin{array}{c}4.76 \\
(1.62)\end{array}$ & $\begin{array}{c}4.70 \\
(1.74)\end{array}$ & $\begin{array}{c}4.91 \\
(1.64)\end{array}$ & $\begin{array}{c}4.59 \\
(1.94)\end{array}$ & $\begin{array}{c}4.80 \\
(1.64)\end{array}$ \\
\hline Self-worth & $\begin{array}{c}3.13 \\
(0.55)\end{array}$ & $\begin{array}{c}3.23 \\
(0.47)\end{array}$ & $\begin{array}{c}3.15 \\
(0.51)\end{array}$ & $\begin{array}{c}3.34^{* *} \\
(0.51)\end{array}$ & $\begin{array}{c}3.17 \\
(0.49)\end{array}$ & $\begin{array}{c}3.21 \\
(0.55)\end{array}$ & $\begin{array}{c}3.15 \\
(0.52)\end{array}$ & $\begin{array}{c}3.28 \\
(0.49)\end{array}$ & $\begin{array}{c}3.07 \\
(0.52)\end{array}$ & $\begin{array}{c}3.21 \\
(0.51)\end{array}$ \\
\hline Depression & $\begin{array}{c}2.65 \\
(1.20)\end{array}$ & $\begin{array}{r}2.42^{\dagger} \\
(1.02)\end{array}$ & $\begin{array}{c}2.57 \\
(1.10)\end{array}$ & $\begin{array}{c}2.29^{*} \\
(1.11)\end{array}$ & $\begin{array}{c}2.50 \\
(1.10)\end{array}$ & $\begin{array}{c}2.57 \\
(1.12)\end{array}$ & $\begin{array}{c}2.57 \\
(1.09)\end{array}$ & $\begin{array}{c}2.41 \\
(1.15)\end{array}$ & $\begin{array}{c}2.72 \\
(1.20)\end{array}$ & $\begin{array}{c}2.48 \\
(1.08)\end{array}$ \\
\hline Risk behavior & $\begin{array}{c}1.70 \\
(0.71)\end{array}$ & $\begin{array}{c}1.70 \\
(0.73)\end{array}$ & $\begin{array}{c}1.73 \\
(0.74)\end{array}$ & $\begin{array}{c}1.58 \\
(0.61)\end{array}$ & $\begin{array}{c}1.75 \\
(0.72)\end{array}$ & $\begin{array}{c}1.63 \\
(0.71)\end{array}$ & $\begin{array}{c}1.76 \\
(0.73)\end{array}$ & $\begin{array}{c}1.53 \\
(0.66)\end{array}$ & $\begin{array}{c}1.82 \\
(0.71)\end{array}$ & $\begin{array}{c}1.68 \\
(0.72)\end{array}$ \\
\hline Alcohol use & $\begin{array}{c}2.63 \\
(2.06)\end{array}$ & $\begin{array}{c}2.81^{*} \\
(2.07)\end{array}$ & $\begin{array}{c}2.66 \\
(2.05)\end{array}$ & $\begin{array}{c}3.07 \\
(2.10)\end{array}$ & $\begin{array}{c}2.91 \\
(2.12)\end{array}$ & $\begin{array}{c}2.38^{*} \\
(1.90)\end{array}$ & $\begin{array}{c}2.89 \\
(2.10)\end{array}$ & $\begin{array}{c}2.22^{* *} \\
(1.88)\end{array}$ & $\begin{array}{c}2.84 \\
(2.14)\end{array}$ & $\begin{array}{c}2.69 \\
(2.05)\end{array}$ \\
\hline Prosocial peers & $\begin{array}{c}3.81 \\
(1.02)\end{array}$ & $\begin{array}{r}4.07^{\dagger} \\
(0.98)\end{array}$ & $\begin{array}{c}3.85 \\
(0.99)\end{array}$ & $\begin{array}{l}4.47^{* * *} \\
(0.95)\end{array}$ & $\begin{array}{c}3.83 \\
(0.99)\end{array}$ & $\begin{array}{c}4.16^{*} \\
(1.00)\end{array}$ & $\begin{array}{c}3.75 \\
(0.96)\end{array}$ & $\begin{array}{l}4.54^{* * *} \\
(0.90)\end{array}$ & $\begin{array}{c}3.39 \\
(0.84)\end{array}$ & $\begin{array}{l}4.10^{* * *} \\
(0.99)\end{array}$ \\
\hline
\end{tabular}

Note. $N=462$; grade-level, gender, grade point average, and parent education included as controls.

${ }^{*} p<0.05,{ }^{* *} p<0.01,{ }^{* *} p<0.001,{ }^{\dagger} p<0.1$.

indicators of adolescent adjustment was not significant, after adjusting for gender, grade-level, parent education, and grade point average.

\section{Academic Clubs}

Participation in academic clubs was associated with lower alcohol use $(F[6,455]=8.09, p<.01)$ and more favorable perceptions of the peer group $(F[6,455]=$ $32.00, p<0.001)$. Similar to the findings for performing arts, there was no relation between participation in academic clubs and the other developmental outcomes.

\section{ANALYSES II: MEDIATIONAL ANALYSES}

In the next set of analyses, we assessed activity participation with the 2 time use measures. A series of regressions were run to examine whether perceptions of a prosocial peer group mediated the relation between time in school clubs and time in organized sports and indicators of adjustment. Figure 1 show the hypothesized mediational links. We were not able to test this model across each of the 4 activity contexts because time use data was not collected on specific clubs and organizations. We ran separate models for school clubs and sports and for each developmental outcome (i.e., school belonging, school affect, self-worth, depression, risk behavior, and alcohol use).

To conclude that there is evidence of mediated relations, the following conditions must be met: (1) significant links between the predictors and outcomes, (2) significant relations between the predictors and the mediator, and (3) significant links between the mediator and the outcomes when all the variables are entered into the same equation, and these relations must reduce the direct effects of the predictors on the outcomes (Baron and Kenny, 1986). Full mediation occurs when the association between the predictor and outcome becomes nonsignificant in the presence of the mediator. Sequential regression analyses were conducted to test each of the 3 conditions for mediation. First, to test for direct effects (Condition 1), each of the developmental outcomes was regressed on the time use measures and statistical controls (i.e., gender, grade-level, parent education, and grade point average). Once a direct link between activity participation and the developmental outcomes was established, the peer group measure was regressed on time in activities (Condition 2). In order to satisfy Condition 3 , the last analyses involved regressions that included both time in activities (predictors) and the peer group measure (mediator) on the developmental outcomes. In instances where these conditions of mediation were satisfied, indirect effects, their standard errors, and their level of significance were calculated (Baron and Kenny, 1986; Sobel, 1982).

\section{Bivariate Relations}

Summary statistics and correlations among all the measures in the model are presented in Table II. In general, the bivariate relations among activity involvement, prosocial peers, and the developmental outcomes exhibited the predicted pattern. Time in organized school clubs was positively associated with school belonging, school 


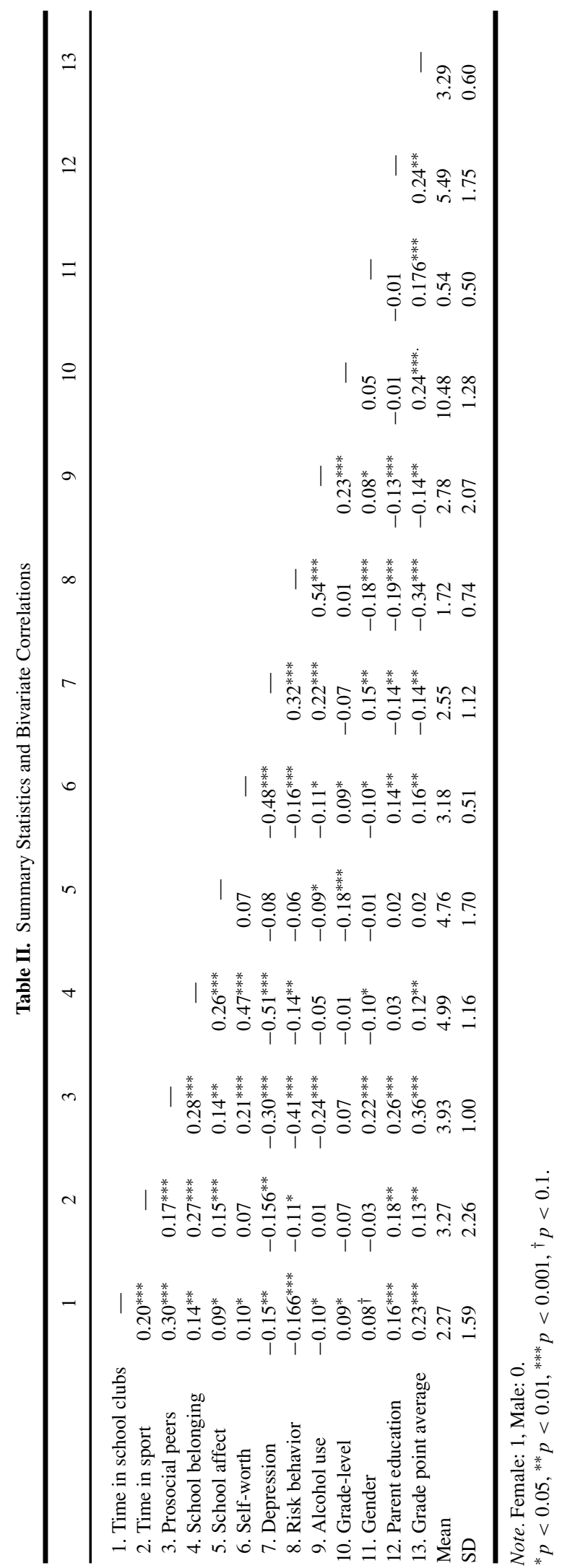


Table III. Standardized Regressions Predicting Positive Outcomes From Time in Organized Clubs

\begin{tabular}{|c|c|c|c|c|c|c|}
\hline \multirow[b]{2}{*}{ Organized clubs } & \multicolumn{2}{|c|}{ School belonging } & \multicolumn{2}{|c|}{ School affect } & \multicolumn{2}{|c|}{ Self-worth } \\
\hline & Model 1 & Model 2 & Model 1 & Model 2 & Model 1 & Model 2 \\
\hline \multicolumn{7}{|l|}{ Step 1 variables } \\
\hline Time clubs & $0.12^{*}$ & 0.06 & $0.10^{*}$ & 0.07 & 0.06 & .02 \\
\hline Grade-level & -0.05 & -0.04 & $-0.20^{* * *}$ & $-0.20^{* * *}$ & 0.06 & .07 \\
\hline Gender & $-0.12^{* *}$ & $-0.17^{* * *}$ & $-0.01^{* *}$ & -0.04 & $-0.13^{* *}$ & $-0.15^{* *}$ \\
\hline Parent education & -0.04 & $-0.09^{\dagger}$ & -0.02 & -0.02 & $0.10^{\dagger}$ & 0.06 \\
\hline Grade-point average & $0.13^{*}$ & 0.06 & 0.04 & 0.00 & $0.13^{*}$ & $0.09^{\dagger}$ \\
\hline \multicolumn{7}{|l|}{ Step 2 variables } \\
\hline Prosocial peers & & $0.29^{* * *}$ & & $0.15^{* *}$ & & $0.18^{* *}$ \\
\hline Change in $F$ & $3.68^{* *}$ & $33.70^{* * *}$ & 3.68 & $8.10^{* * *}$ & $4.68^{* * *}$ & $12.10^{* * *}$ \\
\hline Total adjust. $R^{2}$ & & 0.10 & & 0.05 & & 0.07 \\
\hline
\end{tabular}

affect, and self-worth. In addition, participation in school clubs was a significant negative predictor of depression, risk behavior, and alcohol use. Similarly, time in organized sports was positively related to school engagement and negatively correlated with depression and level of risk behavior; there was no relation between time in sports and self-worth and time in sports and alcohol use. Finally, individuals who spent more time in sports and school clubs reported having more prosocial peers.

\section{Link Between Time in Activities and Developmental Outcomes}

\section{Time in Organized Clubs}

The results of the regressions are presented in Tables III and IV. The direct effects of time in activi- ties on our indicators of adolescent adjustment are found in Model 1. After taking into account entry characteristics, time in school clubs had a positive direct relation with school belonging $(\beta=0.12, p<0.05)$ and school affect $(\beta=0.10, p<0.05)$. In addition, participation in organized clubs was negatively associated with depression $(\beta=-0.11, p<0.05)$. After controlling for gender, grade-level, parent education, and grade point average, time in organized clubs was not related to self-worth or either indicator of risk behavior.

\section{Time in Organized Sports}

The results are presented in Tables V and VI. Time in sports was a significant predictor of school belonging $(\beta=0.26, p<0.001)$ and school affect $(\beta=0.13, p<$ 0.01 ) and a marginally significant predictor of alcohol

Table IV. Standardized Regressions Predicting Negative Outcomes From Time in Organized Clubs

\begin{tabular}{|c|c|c|c|c|c|c|}
\hline \multirow[b]{2}{*}{ Organized clubs } & \multicolumn{2}{|c|}{ Depression } & \multicolumn{2}{|c|}{ Risk behavior } & \multicolumn{2}{|c|}{ Alcohol use } \\
\hline & Model 1 & Model 2 & Model 1 & Model 2 & Model 1 & Model 2 \\
\hline \multicolumn{7}{|l|}{ Step 1 variables } \\
\hline Time clubs & $-0.11^{*}$ & -0.05 & -0.07 & -0.01 & -0.07 & -0.02 \\
\hline Grade-level & -0.05 & -0.05 & $.09^{*}$ & $0.09^{*}$ & $0.26^{* * *}$ & $0.26^{* * *}$ \\
\hline Gender & $0.18^{* * *}$ & $0.23^{* * *}$ & $-0.13^{* *}$ & $-0.08^{\dagger}$ & $0.10^{* *}$ & $0.14^{* *}$ \\
\hline Parent education & -0.05 & 0.00 & -0.06 & -0.01 & -0.02 & .02 \\
\hline Grade-point average & $-0.12^{*}$ & -0.05 & $-0.31^{* * *}$ & $-0.24^{* * *}$ & $-0.20^{* * *}$ & $-0.14^{* *}$ \\
\hline \multicolumn{7}{|l|}{ Step 2 variables } \\
\hline Prosocial peers & & $-0.31^{* * *}$ & & $-0.30^{* * *}$ & & $-0.23^{* * *}$ \\
\hline Change in $F$ & $6.75^{* * *}$ & $39.09^{* * *}$ & $14.61^{* * *}$ & $41.21^{* * *}$ & $10.54^{* * *}$ & $22.38^{* * *}$ \\
\hline Total adjust. $R^{2}$ & & 0.16 & & 0.22 & & 0.15 \\
\hline
\end{tabular}

Note. Female: 1 , Male: 0.

$N=459,{ }^{*} p<0.05,{ }^{* *} p<0.01,{ }^{* * *} p<0.001,{ }^{\dagger} p<0.1$. 
Table V. Standardized Regressions Predicting Positive Outcomes From Time in Organized Sports

\begin{tabular}{|c|c|c|c|c|c|c|}
\hline \multirow[b]{2}{*}{ Organized sports } & \multicolumn{2}{|c|}{ School belonging } & \multicolumn{2}{|c|}{ School affect } & \multicolumn{2}{|c|}{ Self-worth } \\
\hline & Model 1 & Model 2 & Model 1 & Model 2 & Model 1 & Model 2 \\
\hline \multicolumn{7}{|l|}{ Step 1 variables } \\
\hline Time sport & $0.26^{* * *}$ & $0.23^{* * *}$ & $0.13^{* *}$ & $0.12^{*}$ & 0.04 & .02 \\
\hline Grade-level & -0.02 & -0.02 & $-0.18^{* * *}$ & $-0.19^{* *}$ & 0.07 & 0.07 \\
\hline Gender & $-0.10^{*}$ & $-0.15^{* * *}$ & 0.00 & -0.03 & $-0.12^{*}$ & $-0.15^{* *}$ \\
\hline Parent education & -0.07 & $-0.12^{\dagger}$ & 0.00 & -0.03 & 0.09 & .06 \\
\hline Grade-point average & $0.13^{*}$ & 0.05 & 0.04 & 0.00 & $0.14^{* *}$ & $0.09^{\dagger}$ \\
\hline \multicolumn{7}{|l|}{ Step 2 variables } \\
\hline Prosocial peers & & $0.28^{* * *}$ & & $0.15^{* *}$ & & $0.18^{* * *}$ \\
\hline Change in $F$ & $8.03^{* * *}$ & $33.11^{* * *}$ & $4.30^{* * *}$ & $8.65^{* * *}$ & $4.56^{* * *}$ & $12.83^{* *}$ \\
\hline Total adjust. $R^{2}$ & & 0.15 & & 0.06 & & 0.07 \\
\hline
\end{tabular}

use $(\beta=0.08, p<0.1)$. Additionally, time in organized sports was negatively related to depression $(\beta=-0.11$, $p<0.05)$. Finally, after controlling for student entry characteristics, time in sports was not significantly associated with measures of self-worth, risk behavior, or alcohol use.

\section{Link Between Time in Activities and Prosocial Peers}

In order to establish condition \#2 in the hypothesized mediational sequence, the prosocial peers measure was regressed on time in activities and the statistical controls. As hypothesized, time in organized clubs was predictive of prosocial peers $(\beta=0.20, p<0.001)$. Similarly, time in sports was related to prosocial peers $(\beta=0.11, p<$ $0.05)$.

\section{Mediating Effects: Peers to Developmental Outcomes}

\section{School Engagement}

Mediation was tested by regressing each of the outcomes on the activity variable and statistical controls in the presence of prosocial peers. The mediation findings are presented in Tables III and V under the column labeled "Model 2." For school belonging, time on school clubs $(\beta=0.12, p<0.01)$ and time in sports $(\beta=0.26, p<0.001)$ were significant predictors (see "Model 1"). Prosocial peers were a significant predictor of school belonging in the model for school clubs. In the presence of prosocial peers, the relation between time in school clubs and school belonging dropped to nonsignificance ( $\beta=0.06, \mathrm{~ns}$ ). These results satisfy the 3 rd condition for mediation (Baron and

Table VI. Standardized Regressions Predicting Negative Outcomes From Time in Sports

\begin{tabular}{|c|c|c|c|c|c|c|}
\hline \multirow[b]{2}{*}{ Organized sports } & \multicolumn{2}{|c|}{ Depression } & \multicolumn{2}{|c|}{ Risk behavior } & \multicolumn{2}{|c|}{ Alcohol use } \\
\hline & Model 1 & Model 2 & Model 1 & Model 2 & Model 1 & Model 2 \\
\hline \multicolumn{7}{|l|}{ Step 1 variables } \\
\hline Time sports & $-0.11^{*}$ & -0.08 & -0.05 & -0.02 & $0.08^{\dagger}$ & $0.10^{*}$ \\
\hline Grade-level & -0.06 & -0.06 & $-0.08^{\dagger}$ & $0.09^{*}$ & $0.27^{* * *}$ & $0.27^{* * *}$ \\
\hline Gender & $0.17^{* * *}$ & $0.22^{* * *}$ & $-0.13^{* *}$ & $-0.08^{\dagger}$ & $0.10^{*}$ & $0.14^{* *}$ \\
\hline Parent education & -0.04 & 0.01 & -0.06 & -0.01 & -0.04 & 0.01 \\
\hline Grade-point average & $-0.13^{* *}$ & -0.05 & $-0.32^{* * *}$ & $-0.24^{* * *}$ & $-0.22^{* * *}$ & $-0.15^{* * *}$ \\
\hline \multicolumn{7}{|l|}{ Step 2 variables } \\
\hline Prosocial peers & & $-0.31^{* * *}$ & & $-0.30^{* * *}$ & & $-0.25^{* * *}$ \\
\hline Change in $F$ & $6.77^{* * *}$ & $41.04^{* * *}$ & $14.35^{* * *}$ & $42.72^{* * *}$ & $10.68^{* * *}$ & $27.20^{* * *}$ \\
\hline Total adjust. $R^{2}$ & & 0.15 & & 0.22 & & 0.16 \\
\hline
\end{tabular}

Note. Female: 1, Male: 0.

$N=459,{ }^{*} p<0.05,{ }^{* *} p<0.01,{ }^{* * *} p<0.001,{ }^{\dagger} p<0.1$. 
Kenny, 1986). As predicted, the indirect effect of time in school clubs on school belonging through prosocial peers was significant $(\beta=0.06, p \leq 0.001)$. In contrast, the relation between athletic time use and school belonging was not significantly reduced when prosocial peers was added to the model.

Time in school clubs $(\beta=0.10, p<0.05)$ and time in sports $(\beta=0.13, p<0.01)$ were positively associated with school affect. Prosocial peers was also related to positive affect $(\beta=0.15, p<0.01)$. When we included prosocial peers in the model, the relation between time in school clubs and school affect dropped to nonsignificance ( $\beta=0.07, \mathrm{~ns})$. Together, these results satisfy Baron and Kenny's (1986) criteria for mediation. The indirect effect of participation in organized clubs on school affect through positive peers was significant $(\beta=0.03$, $p<0.05)$. In contrast, the association between athletic time use and school affect was not significantly reduced when prosocial peers was added to the regression model.

\section{Psychological Outcomes}

For depression, evidence for mediation was found (see Tables IV and VI). Time in school clubs $(\beta=-0.11$, $p<0.05)$ and time in sports $(\beta=-0.11, p<0.05)$ were significant predictors in Model 1. Prosocial peers was negatively related to depression $(\beta=-0.31, p<0.001)$. After including prosocial peers, in both models the direct relation between activity participation and depression dropped to nonsignficance. Together, these results satisfy Baron and Kenny (1986) criteria for mediation. The indirect effect of activity participation (i.e., time in school; time in sports) on depression through prosocial peers was significant $(\beta=-0.06, p<0.001 ; \beta=-0.03, p<$ 0.05 ). Since the 1 st condition of mediation was not established in the regressions predicting self-worth from activity time use, no further analyses were conducted.

\section{Risk Behavior}

After controlling for gender, grade-level, parent education, and grade point average, the direct effect of time use on both indicators of risk was not significant. Thus, the 1 st condition for mediation was not established in either of the regressions predicting risk behavior and alcohol use and no additional analyses were conducted.

\section{DISCUSSION}

This paper contributes to the literature on extracurricular participation, peers, and adolescent development by: (a) examining the relation between activity participation and development across a range of activity contexts, after adjusting for some self-selection factors, (b) including indicators of both positive and negative adjustment in the same study, and (c) testing whether peer characteristics mediate the link between activity participation and development.

\section{Correlates of Extracurricular Participation}

In general, our results are consistent with prior research showing the developmental benefits of extracurricular participation. We documented support for our hypothesis that involvement in structured activities will relate positively to school engagement. These results support Finn's (1989) participation-identification model, which assumes that extracurricular involvement increases students' identification with school and that academic benefits result from this increased identification. In addition, we found that activity participation was related to lower depression. Some possible explanations for the psychological benefits of activity participation include the opportunity to develop social relationships, the increased sense of belonging, and the chance to be involved in a highly valued activity. In contrast, our hypothesis that activity participation would be associated with lower risk behaviors was not supported. This may reflect the relatively low level of risk in this sample, as compared with previous studies that have documented the protective benefits of extracurricular participation among high-risk youth (Mahoney, 2000; Mahoney and Cairns, 1997). A natural question arising from our cross-sectional analyses is whether activity participation leads to beneficial outcomes or whether psychological assets and school belonging predict involvement in extracurricular activities. In future work, we plan to use longitudinal data to test the causal ordering of extracurricular participation and development.

Few studies have compared the differential effects of participation in specific activities (see Eccles and Barber, 1999; Marsh and Kleitman, 2002 for exceptions). We also found that the pattern of associations differed depending on the type of activity and outcome being considered. For example, both athletes and adolescents in school involvement activities reported significantly higher school belonging than nonparticipants; there was no such relation for the performing arts and academic clubs. Athletes, cheerleaders, and members of student government tend to have higher status in the school and are typically given more public recognition from their peers and both school-related and non-school related adults than 
adolescents who are not involved in these activities (Eder and Parker, 1987). This status and visibility is likely to translate into a stronger sense of identification with the school.

Consistent with the findings of Eccles and Barber (1999), athletes reported higher alcohol use than did nonathletes, while adolescents in the performing arts and academic clubs drank significantly less than did adolescents who did not participate in these activities. This finding also has methodological implications. If participation rates had been aggregated across the 4 activity contexts, the difference in alcohol use would not have been detected. The domain difference in alcohol use may reflect variations in the values, social dynamics, and prevalence of drinking in the peer culture in the 4 activity contexts. To test this hypothesis we compared the proportion of peers who drink regularly and get drunk in each of the activity contexts. Adolescents in school involvement activities reported having peers with the highest alcohol use, followed by adolescents in team sports, the performing arts, and academic clubs.

\section{Peers, Extracurricular Participation, and Adolescent Development}

As hypothesized, we found that participation in school-based extracurricular activities predicted characteristics of one's friendship network. Consistent with findings reported by Eccles and her colleagues (see Eccles et al., 2003; Eccles and Barber, 1999), adolescents in each of the extracurricular contexts reported having more academic and prosocial friends than nonparticipants. Being part of a prosocial peer network explained some of the positive associations of activity participation with school engagement and lack of depression. It is likely that peers influence school engagement and depression in both indirect and direct ways. For example, peers may positively reinforce conventional behaviors, may exert pressure toward school involvement, and may model positive affect and commitment to academic endeavors. Prosocial peers may also help to buffer against depression by providing social support, by teaching social skills, and by helping to reduce alienation.

Coleman (1961) argued that the adolescent peer society and emphasis on extracurricular activities might undermine academic pursuits. There have been several criticisms of Coleman's portrayal of adolescents in extracurricular activities (e.g., Brown, 1990; Holland and Andre, 1987). Our findings also counter Coleman's claim, instead suggesting that the developmental benefits of extracurricular participation are partly a function of as- sociating with a peer group that values academic and conventional norms. Clearly more studies exploring the links between activity participation, peer characteristics, and development across a variety of samples are needed. Moreover, the field clearly could benefit from ethnographic studies (for example, Eder and Parker, 1987; Kinney, 1993) that explore the subcultures and everyday experiences of teenagers in different extracurricular activities.

These results need to be interpreted in light of several methodological decisions. First, the sample was purposely drawn from middle-class families who are in schools with opportunities and resources to support extracurricular involvement. Our findings illustrate that extracurricular participation is associated with positive adjustment in a nondistressed population. More research on the consequences of activity participation across a variety of ecological contexts is clearly needed. Second, in this study, we used cross-sectional data and controlled for factors that influence selection into activities including gender, gradelevel, parent education, and grade point average. However, the claim that extracurricular activities are beneficial for adolescent development is more adequately tested by longitudinal studies where the outcome variable is measured on multiple occasions (Larson, 2000). Without longitudinal data, it is also not possible to determine how much our findings are a function of selection, or the tendency of friends to choose peers with similar characteristics, or socialization, the tendency of friends to shape attributes in each other over time (Berndt, 1992). In future studies, we plan to use longitudinal data to further examine links between activity participation, peer characteristics, and development. Third, we do not have data on the nature or the quality of the extracurricular participation, factors that are likely to influence the relation between activity involvement and adolescent functioning. Fourth, we measured peer characteristics by asking adolescents to report on their friends' values and behavior. One concern is that using perceived reports of peer behavior rather than surveying adolescents' friends about their own behavior inflates the relations between peers' and respondents' behavior (Bauman and Ennett, 1996; Berndt and Keefe, 1995). Although this is a valid methodological critique, we believe that the use of perceived reports of peer behavior is justified because we believe that what adolescents think about their friends is more important than what peers actually do.

In sum, both youth policy advocates and developmental scholars have recommended increased opportunities for extracurricular participation (e.g., Eccles and Gootman, 2002). In many high schools, youth report high levels of boredom, classroom interactions are structured, 
and there are few opportunities for social interaction (Larson, 2000). In contrast, extracurricular activities provide settings within the school where adolescents can interact with peers, participate in activities of common interest which offer both challenge and enjoyment, and be supervised by supportive adults. Unfortunately, participation in high school extracurricular activities is often viewed as nonessential and one of the 1st items to be cut during fiscal constraints. Our results add to a growing literature that suggests that educators should reevaluate these assumptions because of the potential developmental benefits of participation for many high school adolescents.

\section{APPENDIX}

\section{Items Used in Analyses}

List of Measures Used in Analyses

Team Sports (1: participated in at least 1 activity during school year, 0: did not participate)

(1) Baseball

(2) Volleyball

(3) Track/Cross Country

(4) Gymnastics

(5) Tennis

(6) Swimming/Diving

(7) Softball

(8) Basketball

(9) Soccer

(10) Football

(11) Ice Skating

(12) Ice Hockey

(13) Wrestling

(14) Field Hockey

School Involvement Activities (1: participated in at least 1 activity during school year, 0 : did not participate)

(1) Student Government

(2) Pep Club/Boosters

(3) Cheerleading

Performing Arts (1: participated in at least 1 activity during school year, 0 : did not participate)

(1) Band or Orchestra

(2) Dance

(3) Drama

(4) Art

Academic Clubs (1: participated in at least 1 activity during school year, 0: did not participate)

(1) Science Fair

(2) Math Club

(3) Debate Club

(4) Foreign Language Club
(5) Chess Club

(4) Computer Club

(5) Career-Related Club

(7) Literacy Magazine

Activity Time Use

Think about the kinds of things you usually do after school and on weekends. About how many hours each week do you usually spend on organized sports?

About how many hours each week do you usually spend participating in any school club or organization?

(1: none, 2: 1 h or less, 3: 2-3 h, 4: 4-6 h, 5: 7-10 h, 6:

11-15 h, 7: 16-20 h, 8: 21 or more $h)$

School Belonging $(\alpha=0.79,5$ items)

How often do you feel (1: never, 7: all of the time):

(1) Left out of things?

(2) Lonely?

(3) That I really belonged in this school?

(4) That I mattered at this school?

(5) Good about yourself?

School Affect

(1) Compared to last year how much do you like school? (1: a lot less, 7: a lot more)

Depression ( $\alpha=0.87,9$ items)

How often during the last month have you (1: almost never, 7: almost always)

(1) Felt so angry that you wanted to smash or break something?

(2) Felt hopeless?

(3) Felt you could not control for temper?

(4) Felt like you don't care anymore?

(5) Felt very sad?

(6) Felt depressed?

(7) Had thoughts of ending your life?

(8) Felt really unhappy because no one wanted you as a friend?

(9) Felt so upset that you wanted to hit or hurt someone?

Risk Behaviors $(\alpha=0.77,7$ items $)$

About how often during the past 6 months did you?

(1: none, 2: once, 3: 2-3 times, 4: 4-6 times, 5: 7-10 times, 6: 11-20 times, 7: 21-30 times, and 8: 31 or more times)

(1) Skip a day of school?

(2) Do something you knew was dangerous just for the thrill of it?

(3) Have contact with police for something you did or something they thought you did?

(4) Damage public property?

(5) Get suspended from school?

(6) Do some pretty risky things because it was a kick?

(7) Get in a fistfight with another child? 
Alcohol Use ( $\alpha=0.95,2$ items)

About how often during the past 6 months did you?

(1: none, 2: once, 3: 2-3 times, 4: 4-6 times, 5: 7-10

times, 6: 11-20 times, 7: 21-30 times, and 8:31 or

more times)

(1) Get drunk?

(2) Drink alcohol?

Prosocial Peers $(\alpha=0.75,6$ items $)$

Think about how many of your friends (1: none, 7 : all)

(1) Encourage you to do your best in school?

(2) Attend religious services?

(3) Think schoolwork is important?

(4) Are involved in student government or other activities?

(5) Plan to go to college?

(6) Think it is important to do volunteer work in their community?

\section{ACKNOWLEDGMENTS}

This research was supported by a Spencer Postdoctoral Fellowship to the 1st author and grant HD17553 from the National Institute for Child Health and Human Development to Jacquelynne Eccles, Allan Wigfield, Phyllis Blumenfeld, and Rena Harold; grant 0089972 from the National Science Foundation to Jacquelynne Eccles and Pamela Davis-Kean; and grants from the W.T. Grant Foundation and the MacArthur Network on Successful Pathways through Middle Childhood to Jacquelynne Eccles. We would like to thank the principals, teachers, students, and parents of the cooperating school districts for their participation in this project. We would also like to thank the following people for their work on the project: Amy Arbreton, Phyllis Blumenfeld, Carol Freedman-Doan, Rena Harold, Janis Jacobs, Toby Jayaratne, Mina Vida, Allan Wigfield, and Kwang Suk Yoon. Finally, we would like to thank Bradford Brown for his helpful feedback on an earlier version of this manuscript.

\section{REFERENCES}

Barber, B. L., Eccles, J. S., and Stone, M. R. (2001). Whatever happened to the jock, the brain, and the princess? Young adult pathways linked to adolescent activity involvement and social identity. J. Adolesc. Res. 16: 429-455.

Baron, R. M., and Kenny, D. A. (1986). The moderator-mediator variable distinction in social psychological research: Conceptual, strategic, and statistical considerations. J. Pers. Soc. Psychol. 51: $1173-1182$.

Bauman, K. E., and Ennett, S. T. (1996). On the importance of peer influence for adolescent drug use: Commonly neglected considerations. Addiction 91: 185-198.

Berndt, T. J. (1992). Friendship and friends' influence in adolescence. Curr. Dir. Psychol. Sci. 1: 156-159.
Berndt, T. J., and Keefe, K. (1995). Friends' influence on adolescents' adjustment to school. Child Dev. 66: 1312-1329.

Brendgen, M., Vitaro, F., and Bukowski, W. M. (2000). Deviant friends and early adolescents' emotional and behavioral adjustment. J. Res. Adolesc. 10: 173-189.

Brown, B. B. (1988). The vital agenda for research on extracurricular influences: A reply to Holland \& Andre. Rev. Educ. Res. 58: 107111.

Brown, B. B. (1990). Peer groups and peer cultures. In Feldman, S., and Elliott, G. R. (eds.), At The Threshold: The Developing Adolescent. Harvard University Press, Cambridge, MA, pp. 171-196.

Coleman, J. S. (1961). The Adolescent Society. Free, New York.

Cooper, H., Valentine, J. C., Nye, B., and Lindsay, J. J. (1999). Relationships between five after-school activities and academic achievement. J. Educ. Psychol. 9: 369-378.

Eccles, J. S., and Barber, B. L. (1999). Student council, volunteering, basketball, or marching band: What kinds of extracurricular involvement matters? J. Adolesc. Res. 14: 10-43.

Eccles, J. S., Barber, B. L., Stone, M., and Hunt, J. (2003). Extracurricular activities and adolescent development. J. Soc. Issues 59: $865-889$.

Eccles, J. S., and Gootman, J. A. (eds.) (2002). Community Programs to Promote Youth Development. National Academy, Washington, DC.

Eckert, P. (1989). Jocks and Burnouts: Social Categories and Identity in the High School. Teachers College, New York.

Eder, D., and Parker, S. (1987). The cultural production and reproduction of gender: The effect of extracurricular activities on peer-group culture. Soc. Educ. 60: 200-214.

Elliot, D. S., Huizinga, D., and Ageton, S. (1985). Explaining Delinquency and Drug Use. Sage, Beverly Hills, CA.

Finn, J. D. (1989). Withdrawing from school. Rev. Educ. Res. 59: 117142 .

Harter, S. (1985). Manual for the Self-Perception Profile for Children: Revision of the Perceived Competence Scale for Children. University of Denver, Denver, CO.

Hawker, D. S. J., and Boulton, M. J. (2000). Twenty years' research on peer victimization and psychosocial maladjustment: A metaanalytic review of cross-sectional studies. J. Child Psychol. Psychiatry 41: 441-445.

Hawkins, J. D., Catalano, R., and Miller, J. (1992). Risk and protective factors for alcohol and other drug problems in adolescence and early adulthood. Implications for substance abuse and prevention. Psychol. Bull. 112: 64-105.

Hogue, A., and Steinberg, L. (1995). Homophily of internalized distress in adolescent peer groups. Dev. Psychol. 31: 897-906.

Holland, A., and Andre, T. (1987). Participation in extracurricular activities in secondary school: What is known, what needs to be known? Rev. Educ. Res. 57: 437-466.

Keefe, K., and Berndt, T. J. (1996). Relation of friendship quality to self-esteem in early adolescence. J. Early Adolesc. 16: 110119.

Kindermann, T. A. (1993). Natural peer groups as contexts for individual development: The case of children's motivation in school. Dev. Psychol. 29: 970-977.

Kinney, D. A. (1993). From nerds to normals: The recovery of identity among adolescents from middle school to high school. Sociol. Educ. 66: $21-40$.

Larson, R. W. (2000). Towards a psychology of positive youth development. Am. Psychol. 55: 170-183.

Lerner, R. M., and Steinberg, L. (eds.) (2004). Handbook of Adolescent Psychology. Wiley, Hoboken, NJ.

Larson, R. W., and Varma, S. (1999). How children and adolescents spend time across the world: Work, play, and developmental opportunities. Psychol Bull. 125: 701-736.

Lipsey, M. W., and Derzon, J. H. (1998). Predictors of violent or serious delinquency in adolescence and early adulthood: A synthesis of longitudinal research. In Loeber, R., and Farrington, D. P. (eds.), Serious and Violent Juvenile Offenders: Risk Factors and Successful Interventions. Sage, Thousand Oaks, CA, pp. 86-105. 
Mahoney, J. L. (2000). School extracurricular activity participation as a moderator in the development of antisocial patterns. Child Dev. 71: 502-516.

Mahoney, J. L., and Cairns, R. B. (1997). Do extracurricular activities protect against early school dropout? Dev. Psychol. 33: 241-253.

Mahoney, J. L., Larson, R. W., and Eccles, J. S. (eds.) (2005). Organized Activities as Contexts of Development: Extracurricular Activities, After-School and Community Programs. Erlbaum, Mahwah, NJ.

Mahoney, J. L., Scheweder, A. E., and Stattin, H. (2002). Structured after-school activities as a moderator of depressed mood for adolescents with detached relations to their parents. J. Community Psychol. 30: 69-86.

Mahoney, J. L., and Stattin, H. (2000). Leisure activities and adolescent antisocial behavior: The role of structure and social context. $J$. Adolesc. 2000: 113-127.

Marsh, H. W., and Kleitman, S. (2002). Extracurricular school activities: The good, the bad, and the non-linear. Harv. Educ. Rev. 72: 464514
McLauglin, M. (2000). Community Counts: How Youth Organizations Matter For Youth Development. National Academy, Washington, DC.

Osgood, D. W., Wilson, J. K., O’Malley, P. M., Bachman, J. G., and Johnston, L. D. (1996). Routine activities and individual deviant behavior. Am. Soc. Rev. 61: 635-655.

Ryan, A. M. (2001). The peer group as a context for the development of young adolescent motivation and achievement. Child Dev. 72 : $1135-1150$.

Sobel, M. E. (1982). Asymptotic intervals for indirect effects in structural equations models. In Leinhart, S. (ed.), Sociological Methodology. Jossey-Bass, San Francisco, pp. 290-312.

Urberg, K. A., Değirmencioğlu, S. M., and Pilgrim, C. (1997). Close friends and group influence on adolescent cigarette smoking and alcohol use. Dev. Psychol. 33: 834-844.

Youniss, J., Yates, M., and Su, Y. (1997). Social integration: Community service and marijuana use in high school seniors. J. Adolesc. Res. 12: 245-262. 